\title{
EFEITO DA COLHEITA SELETIVA DE MADEIRA SOBRE ALGUMAS CARACTERÍSTICAS FÍSICAS DE UM LATOSSOLO AMARELO SOB FLORESTA NA AMAZÔNIA CENTRAL ${ }^{(1)}$
}

\author{
Walane Maria Pereira de Mello-Ivo ${ }^{(2)} \&$ Sheila Ross $^{(3)}$
}

\begin{abstract}
RESUMO
A colheita seletiva de madeira pode vir a ser uma forma sustentável de uso da terra para ecossistemas florestais da Amazônia, uma vez que permite a manutenção de parte considerável da biomassa florestal, diminuindo, assim, a perturbação nas áreas exploradas. Neste sentido, o presente estudo teve como objetivo avaliar o efeito da exploração seletiva de madeira sobre as características físicas de um Latossolo Amarelo. A área de estudo localiza-se a cerca de $80 \mathrm{~km}$ ao norte de Manaus e a vegetação é do tipo Floresta Ombrófila Densa. O número de árvores retiradas com um trator de esteiras D6, por arraste, em 1993, variou de sete a dez árvores/ha (DAP $>55 \mathrm{~cm}$ ). O delineamento experimental foi do tipo blocos ao acaso, com três repetições. Seis tratamentos foram avaliados, equivalendo às seguintes classes de perturbação identificadas na área: trilha de trator, centro de clareira, borda da clareira/floresta, borda da floresta/clareira, floresta remanescente e floresta-controle. A colheita seletiva de madeira provocou modificações nas características físicas do solo, principalmente nas trilhas de trator, e representou, em média, 13,8 \% da área total explorada. Os valores de densidade do solo e resistência à penetração foram maiores para o solo sob estas áreas, enquanto a macroporosidade e o volume de água disponível para as plantas apresentaram-se menores do que nas demais classes de perturbação. Estas classes foram menos afetadas, não se estabelecendo diferenças significativas para as características físicas do solo entre estas e a floresta-controle, indicando, assim, a colheita seletiva como uma prática de menor impacto para o solo dos ecossistemas florestais da Amazônia.
\end{abstract}

Termos de indexação: manejo florestal, compactação, resistência à penetração, porosidade.

(1) Trabalho desenvolvido no projeto BIONTE-Biomassa e Nutrientes em Florestas Manejadas. Instituto Nacional de Pesquisas da Amazônia - INPA e Department for International Development - DFID. Recebido para publicação em março de 2006 e aprovado em agosto de 2006.

(2) Pesquisadora da Embrapa Tabuleiros Costeiros / UEP Rio Largo. Caixa Postal 2013, CEP 57061-970. Maceió (AL). E-mail: walane@cpatc.embrapa.br

(3) AMEC, Earth and Environmental, Unit 1, Pystill Farm, Nercwys, Mold, Flintshire, CH7 4EW, U.K. E-mail: Sheila.Ross@amec.com 


\title{
SUMMARY: EFFECT OF SELECTIVE LOGGING ON SOME PHYSICAL CHARACTERISTICS OF A YELLOW LATOSOL UNDER RAINFOREST IN CENTRAL AMAZONIA STATE
}

\begin{abstract}
Selective logging may become a form of sustainable use of Amazon forest ecosystems since most part of the forest biomass is maintained and the impacts on the exploited area are lower than in comparison to those under other land uses. The objective of this study was to evaluate the effects of selective logging on some soil physical characteristics. The study area lies about $80 \mathrm{~km}$ north of Manaus and the vegetation is a humid tropical rainforest. Seven to ten trees $/$ ha $(D A P>55 \mathrm{~cm})$ were felled and removed by a D6 bulldozer, in 1993. Six disturbance classes were defined in the logged plots, with three replicates each: tractor track, center of clearing, edge of clearing, edge of forest, remaining forest and control forest. Soil under tractor tracks represented $13.8 \%$ of the exploited area, and showed higher values of bulk density, and penetration resistance, and lower macroporosity and available water for plants than the other disturbance classes. The other classes were less affected and no significant differences were observed between their soil properties and the control forest, indicating selective logging as a practice that causes less impact on soils of Amazon forest ecosystems.
\end{abstract}

Index terms: Forest management, soil compaction, penetration resistance, porosity.

\section{INTRODUÇÃO}

A colheita seletiva de madeira pode vir a ser uma forma sustentável de uso da terra para ecossistemas florestais da Amazônia, uma vez que permite a manutenção da maior parte da biomassa florestal, diminuindo, assim, a perturbação nas áreas usadas para produção de madeira. No entanto, a queda de árvores e a utilização de máquinas pesadas para a retirada dessas árvores levam a modificações no funcionamento do sistema, sendo as mudanças nas condições do solo advindas, principalmente, segundo van der Weert (1974), da degradação da estrutura e da remoção parcial da camada superficial. Esta camada é fundamental para a sustentabilidade florestal, visto que concentra grande parte dos nutrientes e determina a capacidade de infiltração do solo.

Os estudos que avaliam o efeito dos diferentes métodos de limpeza de áreas florestais para cultivos agrícolas têm constatado impactos na estrutura do solo (Lal \& Cummings, 1979; Dias \& Nortcliff, 1985; Chauvel et al., 1990); todavia, são escassas as informações sobre o grau e distribuição desse impacto em áreas parcialmente perturbadas (Ferreira et al, 2004). Além disso, o efeito da presença de árvores remanescentes na recuperação da estrutura dos solos é pouco conhecido ou contraditório. Neste sentido, van der Plas \& Bruijnzeel (1993) observaram, doze anos após a colheita seletiva de madeira na Malásia, que não houve recuperação da estrutura do solo nas trilhas de trator; por outro lado, Chauvel et al. (1990), por meio de análises micromorfológicas do solo e de porosimetria, apontaram a importância da presença de raízes de determinadas espécies e da mesofauna na recuperação da estrutura de solos florestais da Amazônia, mesmo em áreas cultivadas mecanicamente.
Isto pode indicar o potencial da floresta remanescente em áreas de colheita seletiva para promover a recuperação da estrutura dos solos (Ferreira et al., 2004), evitando-se os cultivos de recuperação em extensas áreas, como sugerido por Nortcliff \& Dias (1988), para áreas de floresta que sofreram processos de limpeza mecânica.

O presente estudo teve como objetivo avaliar o efeito da colheita seletiva de madeira nas características físicas da camada superficial de um Latossolo Amarelo, seis meses após o manejo da área.

\section{MATERIAL E MÉTODOS}

A área onde foi realizado o experimento localiza-se a cerca de $80 \mathrm{~km}$ ao norte de Manaus $\left(2^{\circ} 38^{\prime} \mathrm{S}\right.$, $60^{\circ} 11^{\prime} \mathrm{W}$ ), apresenta temperatura média em torno de $26,7^{\circ} \mathrm{C}$ e precipitação de aproximadamente $2.000 \mathrm{~mm}^{2} \mathrm{ano}^{-1}$. A vegetação é do tipo Floresta Ombrófila Densa (floresta densa de terra firme) e o solo é classificado como Latossolo Amarelo (Chauvel, 1982). Apresenta no horizonte A $(0-10 \mathrm{~cm}) 866 \mathrm{~g} \mathrm{~kg}^{-1}$ de argila, $14 \mathrm{~g} \mathrm{~kg}^{-1}$ de silte e $120 \mathrm{~g} \mathrm{~kg}^{-1}$ de areia e $50 \mathrm{~g} \mathrm{~kg}^{-1}$ de matéria orgânica. A estrutura desse horizonte é caracterizada como moderada, pequena e média, granular e blocos subangulares. O horizonte $\mathrm{AB}(10-30 \mathrm{~cm})$ apresenta $877 \mathrm{~g} \mathrm{~kg}^{-1}$ de argila, $14 \mathrm{~g} \mathrm{~kg}^{-1}$ de silte, $109 \mathrm{~g} \mathrm{~kg}^{-1}$ de areia e $22 \mathrm{~g} \mathrm{~kg}^{-1}$ de matéria orgânica.

O delineamento experimental foi o de blocos ao acaso, com três repetições. Cada bloco continha uma parcela controle e uma parcela manejada, na qual, com o corte das árvores e a retirada da madeira, formaram-se diferentes ambientes que caracterizaram cinco dos tratamentos estudados. Assim, seis 
tratamentos foram avaliados, equivalendo estes às seguintes classes de perturbação: trilha de trator, centro de clareira, borda da clareira/floresta, borda da floresta/clareira, floresta remanescente e florestacontrole (Figura 1).

A colheita das árvores foi feita durante três semanas, em setembro de 1993. O número de árvores retiradas variou de sete a dez árvores por hectare (DAP > $55 \mathrm{~cm}$ ), sendo a derrubada feita com o uso de motosserra, e a retirada das toras, por arraste, com um trator de esteiras D6. O levantamento de habitats criados após a exploração da área, realizado por Biot et al. (1997), detectou a seguinte freqüência de aparecimento das classes de perturbação, em área: $13,8 \%$ de trilha de trator, $11 \%$ de centro de clareira, $18,4 \%$ de borda de clareira, 33,9 \% de borda de floresta e $22,9 \%$ de floresta remanescente.

A amostragem do solo foi feita seis meses após a colheita. Para a retirada das amostras indeformadas, foram sorteados 22 pontos por parcela manejada e 12 por parcela controle. Em cada ponto, utilizando anéis volumétricos com $71,24 \mathrm{~cm}^{3}(3 \mathrm{~cm}$ de altura e $5,5 \mathrm{~cm}$ de diâmetro), foram retiradas três amostras para determinação de densidade do solo. As amostras foram coletadas nas profundidades de $0-3$ e $4-7 \mathrm{~cm}$. O número de amostras por classe de perturbação variou aleatoriamente de acordo com a freqüência de aparecimento destas classes na área. Para a densidade do solo foi igual a 26 , para TT; 38 , para,

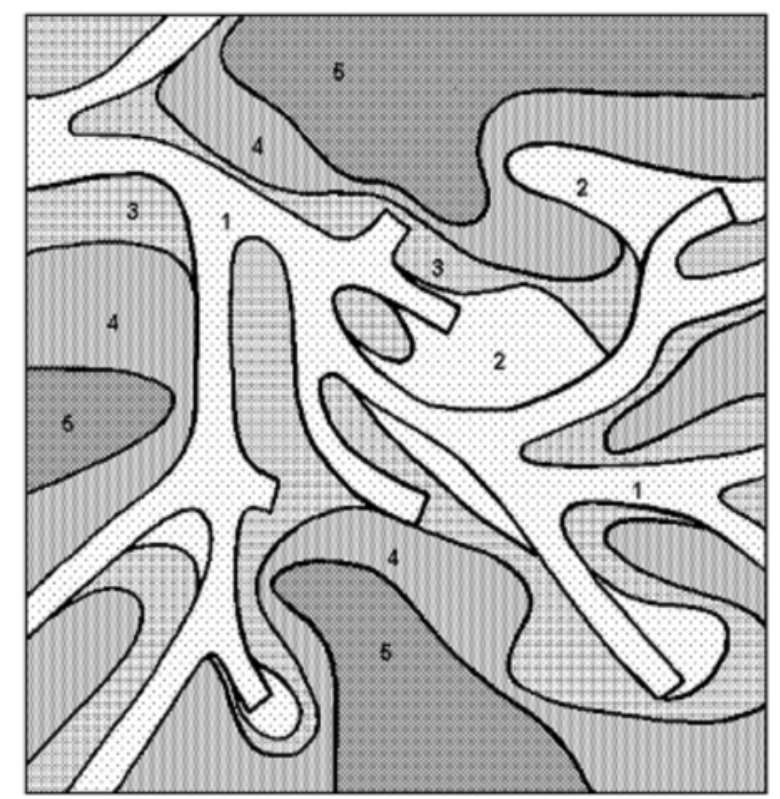

Figura 1. Distribuição espacial das cinco classes de perturbação no hectare central da parcela manejada do bloco $1(100 \times 100 \mathrm{~m})$. Classe 1-trilha de trator (TT), Classe 2-centro da clareira (CC), Classe 3-borda clareira/floresta (BC), Classe 4borda floresta/clareira (BF), Classe 5-floresta remanescente (FR) (Biot et al., 1997).
CC; 48, para BC; 71, para BF; 55, para FR, e 104, para FC. Destas amostras, duas, por classe de perturbação, foram retiradas para construção das curvas de retenção de água, sendo saturadas e colocadas em mesa de tensão e em câmaras de Richards e submetidas a pressões de 1, 6, 10, 30, 100, 200 e $1.500 \mathrm{kPa}$ (Richards, 1965). Com base nestas curvas, foram determinadas as distribuições de tamanho de poros para o solo sob cada classe de perturbação, sendo o diâmetro de poros calculado a partir da equação $p=-\rho g s=-(2 \gamma \cos \alpha) / r($ em que $\rho$ e a densidade da água, g é a aceleração da gravidade, s é

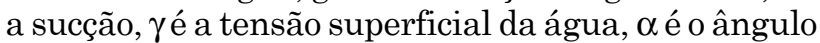
de contato da água e r o raio do poro) (Marshall \& Holmes, 1988). Mais dez amostras, por classe, foram selecionadas para determinação da porosidade total, macro e microporosidade, ficando, ao final, um número de nove para TT e CC, dez para BC e seis para BF, FC e FR . O limite utilizado para distinção entre macro e microporos foi de $6 \mathrm{kPa}$.

Para penetrometria, foram sorteados 24 pontos por parcela derrubada e 12 por controle. Três leituras superficiais foram feitas por ponto, utilizando-se um penetrômetro cônico da ELE International, modelo 293739, composto por anel dinamométrico, manômetro e haste. O número de leitura por classes também foi variável, sendo 18, para a classe TT; 30 , para a classe CC; 45 , para a BC; 81 , para a $\mathrm{BF} ; 42$, para a FR, e 90 , para a FC. Nesta mesma ocasião, foram coletadas amostras deformadas de solo para determinação da umidade gravimétrica e posterior cálculo da umidade volumétrica, utilizando-se a densidade do solo determinada para cada classe de perturbação.

As análises estatísticas foram feitas por meio do software Minitab, utilizando o modelo linear geral (general linear model, GLM) para as análises de variância, uma vez que o número de repetições para as diferentes classes não foi o mesmo para determinadas variáveis. $\mathrm{O}$ teste de Tukey, a $5 \%$, foi usado para separar as médias quando a significância foi indicada.

\section{RESULTADOS E DISCUSSÃO}

Os valores de densidade do solo foram significativamente diferentes entre as duas profundidades estudadas para as classes TT, CC, BC, e BF, com os valores da camada de 4-7 cm apresentando-se mais elevados que os da camada de 0-3 cm (Figura 2). Esta mesma tendência foi observada para as classes FR e FC. A maior quantidade de material orgânico na superfície, conseqüência do maior crescimento de raízes (Guimarães \& Mello Ivo, 1997) e incorporação da liteira (Luizão, 1989), e o revolvimento superficial do solo, em decorrência do rodado das esteiras do trator, justificam a menor densidade na camada de 0-3 cm. Ferreira et al. (2002) 


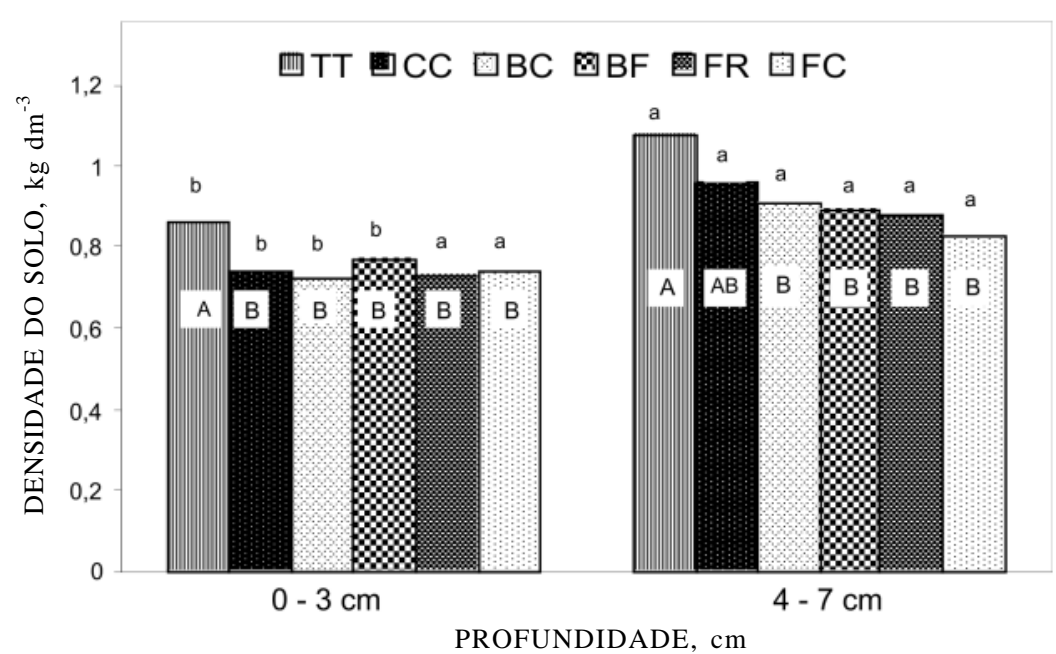

Figura 2. Densidade do solo em diferentes classes de perturbação (TT-trilha do trator; CC -centro da clareira; BC-borda da clareira/floresta; BF-borda da floresta/clareira; FR-floresta remanescente e FC-florestacontrole). Barras (médias) acompanhadas de mesmas letras (maiúsculas para comparar diferentes classes de perturbação, dentro de cada profundidade, e minúsculas para comparar diferentes profundidades, dentro de cada classe de perturbação) não diferem entre si, pelo teste de Tukey a $5 \%$.

encontraram essa mesma tendência de menor valor para a camada de $0-5 \mathrm{~cm}$, quando comparada à de 5$10 \mathrm{~cm}$, tanto em floresta-controle, como em áreas de centro de clareiras. Nas áreas de passagens do trator, onde o impacto da colheita mostrou-se mais intenso, essa diferença pode ser atribuída à camada superficial, mais rica em matéria orgânica, que tende a apresentar diminuição da densidade do solo máxima e um aumento da umidade ótima ou crítica para compactação.

Revendo o processo de compactação dos solos, Dias Junior (2000) coloca que maiores teores de matéria orgânica do solo provocam redução na amplitude das curvas de compactação, diminuindo, conseqüentemente, a densidade de solo máxima e aumentando a umidade ótima ou crítica de compactação. Isso ocorre graças à influência da matéria orgânica no poder de adsorção de água do solo e ao baixo valor de densidade desta última.

Os valores médios encontrados para o controle, nas duas profundidades $\left(0,75\right.$ e $\left.0,82 \mathrm{~kg} \mathrm{dm}^{-3}\right)$, são semelhantes aos relatados por Corrêa (1984) e Ferreira at al. (2004), para Latossolos Amarelos argilosos, localizados em áreas de florestas de terra firme da Amazônia central . Estes valores atingiram, em algumas amostras da superfície, $0,5 \mathrm{~kg} \mathrm{dm}^{-3}$, sendo atribuídos à elevada quantidade de material orgânico nesta camada $\left(\mathrm{C}\right.$ org. $(0-5 \mathrm{~cm})=61,3 \mathrm{~g} \mathrm{~kg}^{-1}$; $\mathrm{C}$ org. $\left.(5-10 \mathrm{~cm})=34,0 \mathrm{~g} \mathrm{~kg}^{-1}\right)$ e à presença de agregados com diâmetro superior a $2 \mathrm{~mm}$, presentes em grande quantidade nestas áreas de floresta (Mello,1994).

O tratamento TT apresentou valores de densidade na camada de $0-3 \mathrm{~cm}$ e de resistência à penetração estatisticamente maiores do que os demais (Figuras 2 e 3). Na profundidade de 4-7 cm, a diferença entre tratamentos repete-se, porém, com uma exceção, por não ter a classe equivalente ao centro de clareira apresentado diferença significativa na densidade, em relação à área de trilha do trator. Estas duas classes foram as que mais sofreram a influência da passagem da máquina e das toras retiradas, principalmente nas trilhas, o que explica os maiores valores. As áreas de trilhas e centro de clareiras apresentaram elevados desvios-padrão, provavelmente em conseqüência das diferentes intensidades com que a máquina trabalhou na área, sendo este trabalho bastante heterogêneo e dependente do tamanho e número de toras que foram retiradas.

Estudando o efeito do número de passagens do trator e da umidade do solo nas propriedades de um Latossolo recém-desmatado, Dias \& Nortcliff (1985) também constataram aumento da densidade do solo e da resistência à penetração, em relação ao controle, para todas as áreas trabalhadas pela máquina. Estes efeitos foram maiores, à medida que o solo encontrava-se mais úmido, e, dentro de cada estado de umidade estudado, as modificações na superfície do solo aumentaram com o número de passagens do trator.

A resistência à penetração depende da densidade do solo e do teor de umidade deste, aumentando com a diminuição da umidade e com o aumento da densidade (Mirreh \& Ketcheson, 1972). Sendo assim, a maior resistência da trilha, em relação às demais classes, seria função da maior densidade do solo sob este tratamento, uma vez que, no momento da leitura, os valores de umidade volumétrica não apresentaram diferença significativa entre as diferentes classes (Figura 4). Essa não diferenciação entre os valores de umidade do solo deveu-se, provavelmente, ao fato de ter a coleta das amostras ocorrido num período da 
estação chuvosa, em que as chuvas foram muito freqüentes.

Apesar de não diferir significativamente quanto à densidade e umidade volumétrica, o solo no centro das clareiras apresentou maior resistência à penetração em relação ao da borda da clareira e da borda da floresta. Essa maior resistência pode ser explicada com base na distribuição de tamanho de poros do solo. Segundo Silva \& Giarola (2001), para solos não saturados, as diferentes pressões com as quais as partículas do solo são conectadas por meio de filmes de água também controlam a resistência à penetração.

Assim, a umidade semelhante nas diferentes classes de perturbação pode estar retida no solo com força diferenciada, dependendo da distribuição de tamanho de poros sob cada classe. Na faixa de umidade no momento da leitura $\left(0,51-0,55 \mathrm{~m}^{3} \mathrm{~m}^{-3}\right)$, as classes de borda de clareira, borda de floresta e floresta remanescente e controle apresentaram maior quantidade de poros sem água e a água retida ocupava, em maior proporção, poros de maior diâmetro, conforme a distribuição de cada classe (Figura 5). Isso pode ter provocado diminuição na resistência mecânica do solo, uma vez que a drenagem desse espaço poroso leva ao aumento da compressibilidade do solo, e a ocupação de poros com maiores diâmetros pela água reflete-se em menor estresse efetivo. Esse aumento da compressibilidade e essa redução do estresse devem ter ocorrido, de forma mais acentuada, nas bordas de clareira e de floresta, decorrente do acúmulo de resúdos orgânicos (folhas e galhos) advindo da permanência

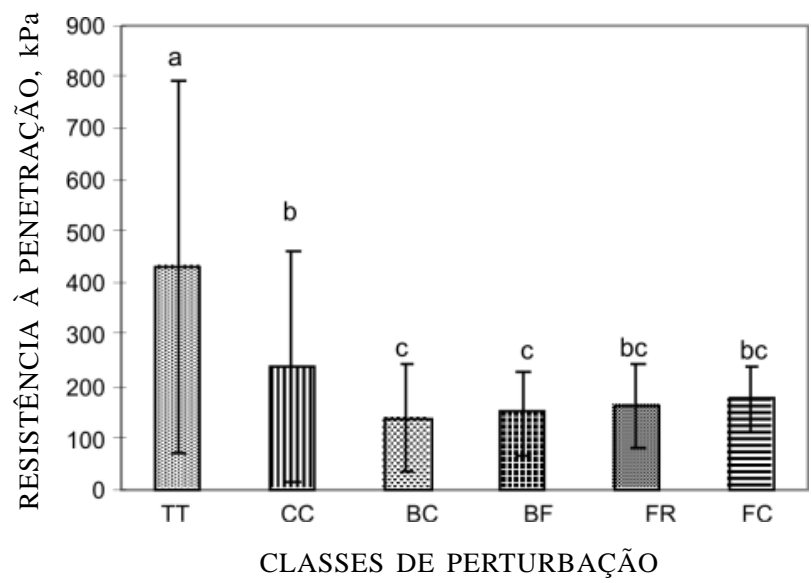

Figura 3. Valores médios e desvios-padrão da resistência à penetração $(\mathrm{kPa})$ em diferentes classes de perturbação $(0-3 \mathrm{~cm})$ (TT-trilha do trator; CC-centro da clareira; BC-borda da clareira/floresta; $\mathrm{BF}$-borda da floresta/clareira; FR-floresta remanescente e FC-florestacontrole). Barras (médias) acompanhadas de mesmas letras não diferem entre si, pelo teste de Tukey a $5 \%$.

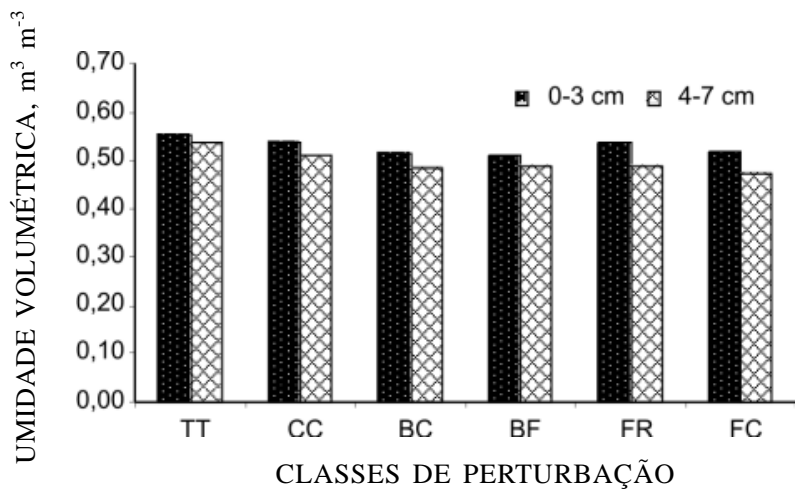

Figura 4. Umidade volumétrica do solo em diferentes classes de perturbação $(0-3$ e $4-7 \mathrm{~cm})$ (TT-trilha do trator; CC-centro da clareira; BCborda da clareira/floresta; BF-borda da floresta/ clareira; FR-floresta remanescente e FC-floresta-controle). Médias seguidas de mesma letra não diferem estatisticamente entre si pelo teste de Tukey, a $5 \%$.

das copas das árvores nestas duas classes, o que justifica o fato de o solo sob floresta remanescente e controle, que também apresentou maior quantidade de poros com raios maiores que $150 \mu \mathrm{m}$ sem água, não ter mostrado diferença do centro de clareira quanto à resistência à penetração. Por sua vez, o solo no centro de clareira, por estar com maior quantidade de poros ocupados pela água, pôde apresentar menor compressibilidade e submeter-se a maiores estresses efetivos.

As modificações da estrutura do solo, evidenciadas pelos valores de densidade do solo e resistência à penetração, também podem ser observadas nos dados contidos no quadro 1. A macroporosidade foi reduzida nas trilhas de trator, ficando o solo com valores em torno de 50 \% do valor das áreas de floresta-controle e demais áreas trabalhadas, o que levou ao aumento dos microporos nesta classe. Sendo assim, a disponibilidade de água para as plantas nestes ambientes pode ter sofrido redução. Essa idéia é reforçada pela distribuição de tamanho de poros para as diferentes classes de perturbação (Figura 5). A trilha do trator apresentou menor percentagem de poros com diâmetro maior que $150 \mu \mathrm{m}$, importantes na distribuição da água dentro do solo, e maior percentagem para as duas classes de menores diâmetros, 0,75-0,09 e < 0,09 $\mu \mathrm{m}$, classes próximas ao limite superior de água disponível, revelando, assim, uma redução na disponibilidade de água. Chauvel et al.(1990) concluíram que o maior efeito da ação de máquinas pesadas sobre o solo em áreas de floresta da amazônia é a redução da macroporosidade e, como conseqüência, ocorre uma redução drástica do volume de água disponível para as plantas. Esses autores quantificaram uma redução de $3 / 4$ no volume de poros que continham água disponível para as plantas. 


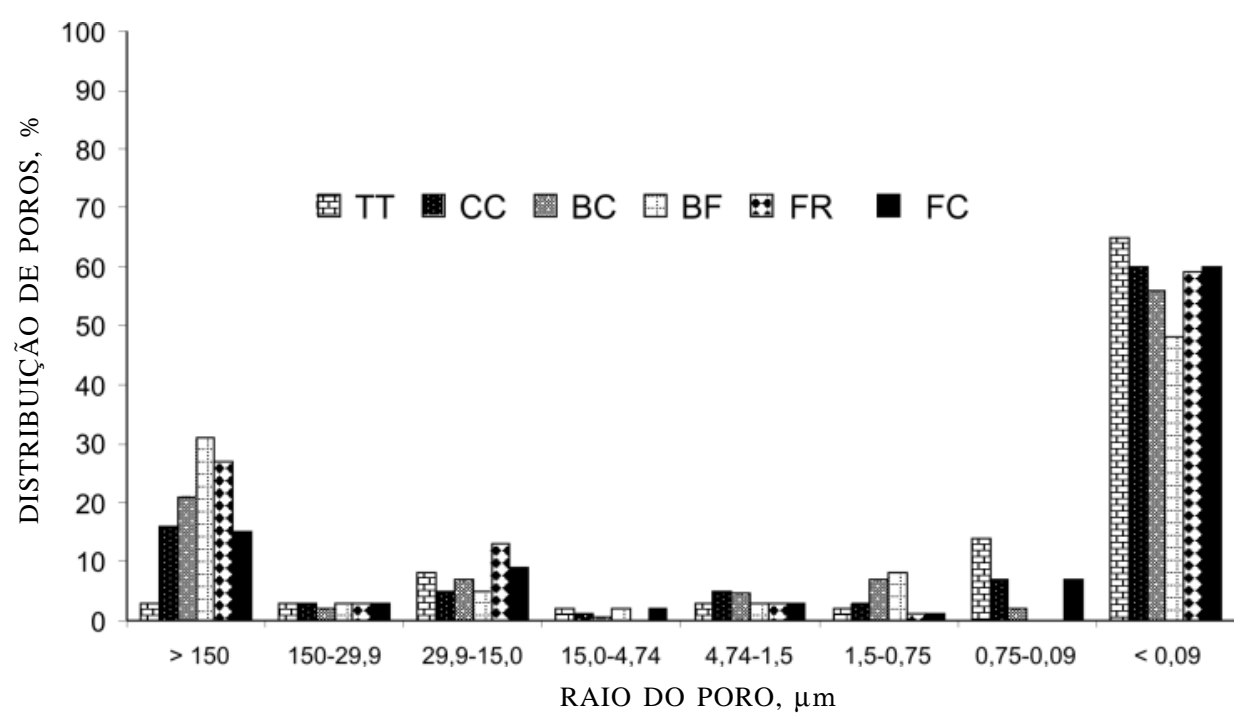

Figura 5. Distribuição de tamanho de poros em diferentes classes de perturbação na camada de 0-3 cm (TTtrilha do trator; CC-centro da clareira, BC-borda da clareira/floresta; BF-borda da floresta/clareira; FRfloresta remanescente e FC-floresta-controle).

Quadro 1. Valores médios e desvios-padrão da macroporosidade, microporosidade e porosidade total em diferentes classes de perturbação (0-3 cm) de um Latossolo Amarelo, submetido à colheita seletiva de madeira. Médias de mesma coluna seguidas de mesma letra não diferem estatisticamente entre si pelo teste de Tukey, a $5 \%$

\begin{tabular}{lccc}
\hline Classe de perturbação & Macroporosidade & Microporosidade & Porosidade Total \\
\hline & & $\mathrm{m}^{3} \mathrm{~m}^{-3}$ & $0,61 \pm 0,04 \mathrm{~b}$ \\
Trilha do trator & $0,11 \pm 0,03 \mathrm{c}$ & $0,51 \pm 0,04 \mathrm{a}$ & $0,68 \pm 0,03 \mathrm{a}$ \\
Centro da clareira & $0,20 \pm 0,03 \mathrm{ab}$ & $0,48 \pm 0,05 \mathrm{ab}$ & $0,67 \pm 0,03 \mathrm{ab}$ \\
Clareira/floresta & $0,18 \pm 0,02 \mathrm{~b}$ & $0,49 \pm 0,04 \mathrm{ab}$ & $0,65 \pm 0,05 \mathrm{ab}$ \\
Floresta/clareira & $0,24 \pm 0,04 \mathrm{a}$ & $0,41 \pm 0,08 \mathrm{~b}$ & $0,64 \pm 0,02 \mathrm{ab}$ \\
Floresta remanescente & $0,21 \pm 0,04 \mathrm{ab}$ & $0,43 \pm 0,05 \mathrm{~b}$ & $0,64 \pm 0,04 \mathrm{ab}$ \\
Floresta-controle & $0,19 \pm 0,01 \mathrm{ab}$ & $0,44 \pm 0,03 \mathrm{ab}$ & \\
\hline
\end{tabular}

Verificou-se, que a classe borda de floresta/clareira apresentou a maior percentagem de poros na classe $>150 \mu \mathrm{m}$ (Figura 5). Notou-se também, uma tendência à maior macroporosidade em relação a todas as classes, sendo esta significativamente diferente apenas em relação à trilha e borda de clareira (Quadro 1). Este fato pode ser conseqüência do mencionado acúmulo de material orgânico naquela classe.

Observando as diferentes curvas de retenção de água no solo (Figura 6) e comparando as diferentes classes de perturbação com as da floresta-controle, nota-se que a única classe que permitiu retenção de maior volume de água que a curva do controle, para quase todas as tensões aplicadas, foi a classe TT, indicando, neste caso, uma diminuição da disponibilidade da água para as plantas nas áreas de trilha do trator.
Avaliando o efeito do grau de compactação na curva característica de água de três solos, submetidos a diferentes sistemas de manejo, Dias Junior \& Stanislau (1999) relataram que, com o aumento do grau de compactação, ocorreu a diminuição da água disponível nos solos estudados. O deslocamento para cima da curva de retenção da TT reflete, mais uma vez, a maior modificação da estrutura do solo, nesta classe. Neste mesmo sentido, Kamaruzaman \& Majid (1996) concluíram que as áreas de trilha de trator apresentaram os maiores distúrbios e compactação do solo, diminuindo, assim, a disponibilidade de água e sendo necessária a adoção de medidas preventivas para eliminar a compactação. Estas medidas estariam ligadas a sistemas de reabilitação de solos em áreas exploradas anteriormente, construções de estradas (Kamaruzaman \& Majid, 1996), redução do número 


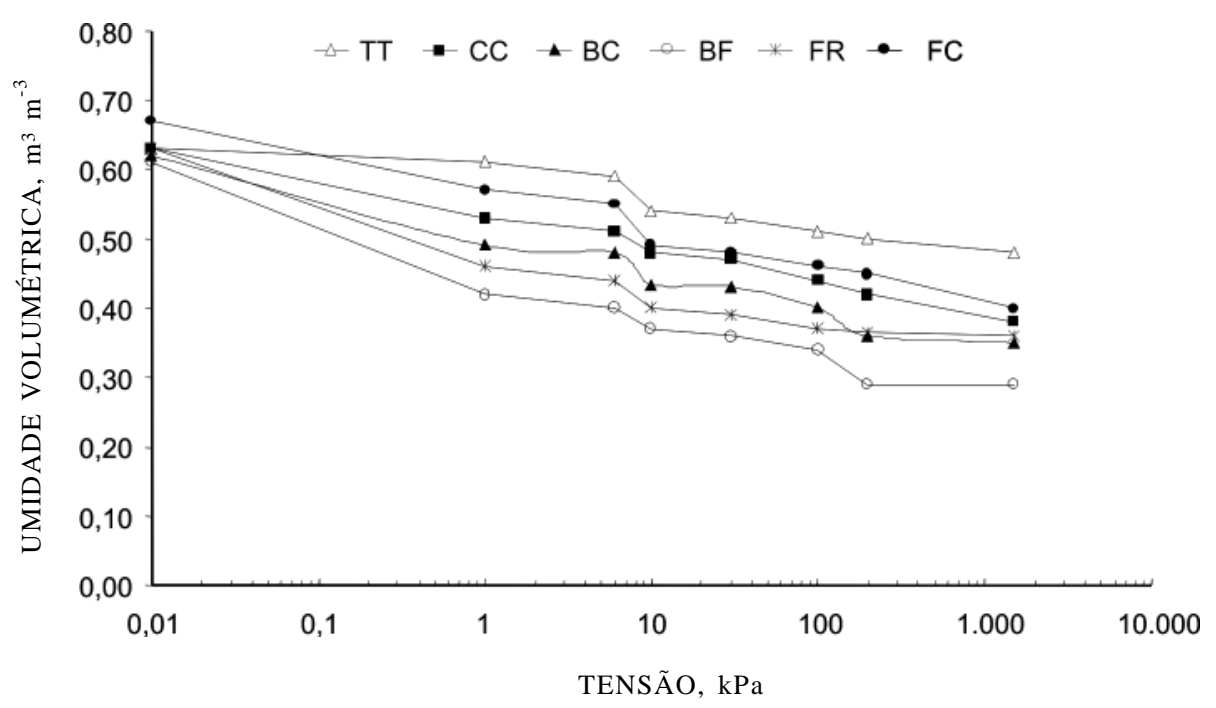

Figuras 6. Curvas de retenção de água de um Latossolo Amarelo (0-3 cm), sob diferentes classes de perturbação (TT-trilha do trator; CC-centro da clareira; BC-borda da clareira/floresta; BF-borda da floresta/clareira; FR-floresta remanescente e FC-floresta-controle).

de passagens do trator, exploração em épocas nas quais o solo estivesse com menor umidade (Dias \& Nortcliff, 1985, Dias Junior, 2000), planejamento da distribuição de áreas de retirada de árvores e das principais trilhas de trator (Gullison \& Hardner, 1993).

As curvas de retenção de água da florestacontrole e da floresta remanescente apresentaram comportamento distinto, embora os dados de densidade do solo, resistência à penetração e porosidade tenham sido semelhantes. Tal distinção está relacionada, provavelmente, com a própria variabilidade espacial encontrada no solo sob floresta, visto que as áreas de floresta remanescente guardaram fortemente as características da floresta-controle, diferindo mais quanto à quantidade de luz que penetrava nestas área. Como apenas duas amostras foram utilizadas para a construção da curva de retenção de cada classe de perturbação, estas podem ter sido retiradas em pontos com maior ou menor acúmulo de resíduos orgânicos (liteira, raízes, galhos, etc.) ou em áreas em que o trabalho de fauna de solo foi mais ou menos pronunciado. Neste sentido, pelo fato de as classes borda de clareira e centro de clareira encontrarem-se com as curvas entre esta faixa de variabilidade, presume-se que a variação entre alguns pontos da floresta não manejada (controle e remanescente) seja superior ou igual à variação entre algumas classes de perturbação, excetuando-se aí a trilha do trator e a borda de floresta, como já comentado anteriormente. Da mesma forma, Ferreira et al. (2002) detectaram grande variabilidade espacial para a condutividade hidráulica de solo saturado, em áreas de florestacontrole e de extração seletiva de madeira na Amazônia e não encontraram diferença entre áreas de centro da clareira e de floresta-controle quanto à disponibilidade de água.

\section{CONCLUSÕES}

1. As áreas de trilha de trator foram as mais afetadas pela colheita seletiva de madeira, com aumento da densidade do solo e da resistência à penetração e diminuição da macroporosidade e da disponibilidade de água.

2. As demais classes de perturbação, centro de clareira, borda clareira/floresta, borda floresta/clareira e floresta remanescente foram menos afetadas, não se estabelecendo diferenças significativas para as características físicas do solo entre estas e as da floresta-controle. Assim, a colheita seletiva foi uma prática de baixo impacto para o solo.

\section{LITERATURA CITADA}

BIOT,Y.; FERRAZ, J.; VIEIRA, G.; LUIZÃO, F. \& MINETTE, L. Levantamento de habitats após a exploração seletiva de madeira. Biomassa e nutrientes florestais. Manaus, MCT-INPA/DFID, 1997. 344p. (Relatório final)

CHAUVEL, A. Os Latossolos Amarelos, álicos, argilosos dentro dos ecossistemas das bacias experimentais do INPA e da região vizinha. Acta Amaz., 12:38-47, 1982.

CHAUVEL, A.; GRIMALDI, M. \& TESSIER, D. Changes in soil pore-space distribution following deforestation and revegetation: An example from the Central Amazon Basin, Brazil. For. Ecol. Manag., 38:1-14, 1990.

CORRÊA, J.C. Características físico hídricas dos solos Latossolo Amarelo, Podzólico Vermelho-Amarelo e Podzol Hibromórfico do Estado do Amazonas. Pesq. Agropec. Bras., 19:347-360, 1984. 
DIAS, A.C.C.P. \& NORTCLIFF, S. Effects of tractor passes on physical properties of an Oxisol in the Brasilian Amazon. Trop. Agric., 62:137-141, 1985.

DIAS JUNIOR, M.S. Compactação do solo. In: NOVAIS, R.F.; ALVAREZ V., V.H. \& SCHAEFER, C.E.G.R., eds. Tópicos em ciência do solo. Viçosa, MG, Sociedade Brasileira de Ciência do Solo, 2000. p.55-94

DIAS JUNIOR, M.S. \& ESTANISLAU, W.T. Grau de compactação e retenção de água de Latossolos submetidos a diferentes sistemas de manejo. R. Bras. Ci. Solo, 23:4551, 1999.

FERREIRA, S.J.F.; LUIZÃO, F.J.; MELLO-IVO, W.M.P.; ROSS, S.M. \& BIOT, Y. Propriedades físicas do solo após extração seletiva de madeira na Amazônia Central. Acta Amaz., 32:449-466, 2002.

FERREIRA, S.J.F.; LUIZÃO, F.J.; ROSS, S.M.; BIOT, Y. \& MELLO-IVO, W.M.P. Soil water storage in an upland forest after a selective logging in Central Amazonia. R. Bras. Ci. Solo, 28:59-66, 2004.

GUIMARÃES, W.M. \& MELLO IVO, W.M.P. Biomassa e nutrientes de raízes finas em área de exploração seletiva de madeira na Amazônia Central, Brasil. Biomassa e nutrientes florestais. Relatório final. Manaus, MCT-INPA/ DFID, 1997. 344p.

GULLISON, R.E. \& HARDNER, J.J. The effects of road design and harvest intensity on forest damage caused by selective logging: Empirical results and simulation model from Bosque Chimanes, Bolívia. For. Ecol. Manag., 59:1-14, 1993.

KAMARUZAMAN, J. \& MAJID, N.M.N. Forest soil compaction from ground-based skidding in Malaysian hill forest. In: CONFERENCE OF THE INTERNATIONAL SOIL CONSERVATION ORGANISATION, 9., Bonn, 1996. Abstracts. Bomm, 1996. p.53.

LAL, R. \& CUMMINGS, D.J. Clearing a tropical forest. I. Effects on soil and micro-climate. Field Crops Res., 2:91-107, 1979.
LUIZÃO, F.J. Litter production and mineral element input to the forest floor in a Central Amazonia forest. Geojournal, 19:407-417, 1989

MARSHALL, T.J. \& HOLMES, J.W. Soil physics. 2.ed. Cambridge, Cambridge University Press, 1988. 374p.

MIRREH, H.F. \& KETCHESON, J.W. Influence of soil bulk density and matric pressure on soil resistance to penetration. Can. J. Soil Sci., 52:477-483, 1972.

MELLO, W. Efeito da derrubada seletiva de madeira na estrutura de um Latossolo sob floresta de terra firme na amazônia central. In: REUNIÃO BRASILEIRA DE MANEJO E CONSERVAÇÃO DO SOLO E DA ÁGUA, 10., Florianópolis, 1994. Resumos. Florianópolis, Sociedade Brasileira de Ciência do Solo, 1994. p.380.

NORTCLIFF, S. \& DIAS, A.C.D.C. The change in soil physical conditions resulting from forest clearance in the humid tropics. J. Biogeog., 15:61-66, 1988.

RICHARDS, L.A. Physical conditions of water in soil. In: BLACK, C.A. ed. Methods of soil analysis. Part 1, Madison, American Society of Agronomy, 1965. 770p.

SILVA, A.P. \& GIAROLA, N.F.B. Estabelecimento de índice de resistência dos solos para quantificação do grau de coesão. In: WORKSHOP SOBRE COESÃO EM SOLOS DOS TABULEIROS COSTEIROS, Aracaju, 2001. Anais. Aracaju, Embrapa Tabuleiros Costeiros, 2001. p.145-160.

van der PLAS, M.C. \& BRUIJNZEEL, L.A. Impact of mechanized selective logging of rainforest on topsoil infiltrability in the Upper Segama area, Sabah, Malaysia. In: HYDROLOGY OF WARM HUMID REGIONS YOKOHAMA SYMPOSIUM, 1993. Proceedings. Local, IAHS, 1993. p.203-211. (Publication, 216)

van der WEERT, R. Influence of mechanical forest clearing on soil conditions and the resulting effects on root growth. Trop. Agric., 51:325-333, 1974. 